\title{
La biopsia de piel a partir de 1960
}

\section{The skin biopsy from 1960}

El año 1960 marcó un cambio trascendente en la técnica de la biopsia cutánea que la simplificaría y multiplicaría por mil.

Veamos, entonces, cuáles eran los métodos de la biopsia de piel hasta ese momento.

Primero.

Durante décadas, se usó el bisturí con sutura. Se necesitaba tener hábito y experiencia quirúrgica para hacerlo con un resultado estéticamente aceptable.

Segundo.

A fines de la década de los cincuenta aparece un sacabocados de acero inoxidable llamado punch en el ambiente dermatológico, que debía introducirse en un torno portátil de dentista. Mediante un pedal se accionaba una turbina que giraba a gran velocidad, produciendo un gran estruendo que hacía temblar a los pacientes. Funcionaba en el laboratorio de patología de la cátedra de Dermatología de Luis E. Pierini en el Hospital Rawson. Esta costosa dupla "punch-torno odontológico" era accionada por Jorge Abulafia, quien se convierte así en el primer protagonista del cambio en la técnica de la biopsia cutánea.

Tercero.

Finalmente, en 1960 irrumpió en el mundo dermatológico el "punch manual” (sin torno). Era un sacabocados de acero que debía esterilizarse con alcohol luego de cada biopsia. Surgen entonces dos nuevos protagonistas del cambio: Augusto Casalá, jefe de Dermatología del Policlínico de Avellaneda y un sacerdote, cuyo nombre nunca supe, amigo de Casalá.

Este sacerdote aficionado a la botánica manejaba habitualmente el punch, biopsiando hojas y flores. Enterado de la necesidad que la dermatología tenía de este instrumento, le regala un ejemplar a su amigo el dermatólogo.

Estamos en presencia de un caso notable: religión y ciencia unidas para el progreso.

Este punch fue el primero que usé a mediados de la década de 1960 y, quizás, haya sido también el primero en la Argentina. Este sencillo instrumento multiplicó las biopsias de piel debido a la facilidad de su uso, el bajo costo y el buen resultado estético.

Pero, como teníamos un solo sacabocados, las biopsias eran muy lentas, pues había que esterilizarlo luego de cada una de ellas. Intervienen entonces dos nuevos protagonistas: un dermatólogo, Carlos A. Bianchi, y un tornero, el Sr. Ruggieri, quienes diseñan un mango en el cual se insertaban los punch que hasta ese momento se insertaban en el ya abandonado torno.

Así se hizo esta historia. Nuestro punch, antes de llegar a la piel humana, pasó por la piel de los vegetales, pues se diseńó en Alemania para usarlo en botánica a fines del siglo XIX.

Como colofón de esta breve anécdota me pregunto: ¿quién se iba a imaginar, en aquellos lejanos años sesenta, que aparecerían los sacabocados descartables que tanto simplificarían las biopsias cutáneas?

Oscar Bianchi Ex jefe del área Dermatopatología de los Hospitales R. Finocchietto, F.J. Muñiz, Italiano y Sanatorio Güemes (Buenos Aires) 